\title{
Erratum to: Modeling and simulation for microscopic traffic flow based on multiple headway, velocity and acceleration difference
}

\author{
Yongfu Li · Dihua Sun · Weining Liu • Min Zhang • \\ Min Zhao $\cdot$ Xiaoyong Liao $\cdot$ Liang Tang
}

Received: 25 July 2010 / Accepted: 1 December 2010 / Published online: 5 October 2011

(C) Springer Science+Business Media B.V. 2011

\section{Erratum to: Nonlinear Dyn (2011) 66:15-28 \\ DOI 10.1007/s11071-010-9907-z}

The grant number of the Fundamental Research Funds for the Central Universities project was missing in the Acknowledgements section of the original publication. The grant number is CDJXS10170002.

The online version of the original article can be found under doi:10.1007/s11071-010-9907-z.

Y. Li $(\varangle) \cdot$ D. Sun · M. Zhang · M. Zhao · X. Liao ·

L. Tang

College of Automation, Chongqing University, Chongqing

400044, China

e-mail: laf1212@163.com

W. Liu

College of Computer, Chongqing University, Chongqing 400044, China 